\title{
Conventional angiography findings in hemodynamically unstable patients with acute abdominal hemorrhage and a negative $\mathrm{CT}$ bleeding study
}

Amy C. O'Brien ${ }^{1}$, Gerard M. Healy' ${ }^{1}$ Nicholas Rutledge ${ }^{2}$, Aishan Patil ${ }^{3}$, Jeffrey W. J. McCann ${ }^{1}$ and Colin P. Cantwell ${ }^{1,4^{*}}$

\begin{abstract}
Background: $C T$ bleeding study (CTA) is regularly requested in acute abdominal haemorrhage (AAH) with haemodynamic instability by clinical teams and interventional radiologists because CTA can; detect arterial bleeding at low rates of hemorrhage, accurately localize the bleeding point and characterize the etiology.

How best to manage an unstable patient who has an AAH with a haematoma and no acute vascular findings on CTA represents a difficult clinical scenario for treating physicians and Interventional Radiologists.

Purpose: To review the conventional angiography (CA) findings and clinical outcome of hemodynamically unstable patients with AAH who had a preceding negative CTA.

Materials and methods: All patients who were hemodynamically unstable and underwent CTA and CA for acute arterial abdominal hemorrhage at our institution between 01/01/2010 and 31/12/2017 were identified. Patients with obstetric, penetrating trauma, abdominal aortic or venous sources of hemorrhage were excluded. Patients who had a negative CTA before CA were included. Patient medical records were reviewed for clinical outcome.

Results: In the study period 160 hemodynamically unstable patients underwent 178 CA procedures. 155 CA procedures were preceded by CTA. 141 CTAs demonstrated active bleeding or an abnormal artery. 14 CTAs in 13 patients demonstrated hematoma but no acute bleeding (mean age $=56$-years; M:F, 12:1). Eight of the 14 CA studies demonstrated: active bleeding $(n=4)$, pseudoaneurysm $(n=1)$ or a truncated artery $(n=3)$. Cases of renal hemorrhage demonstrated a significantly higher proportion of false negative CTA studies (36\%). Selective $(n=8)$ or empiric $(n=4)$ embolization was performed in twelve cases. All patients stopped bleeding and there were no mortalities.
\end{abstract}

Conclusion: In a cohort of hemodynamically unstable patients, 57\% (8/14) of cases with no acute vascular findings on CTA demonstrated a source of hemorrhage on CA. The false negative rate of CTA was significantly higher for renal tract hemorrhage compared to other sites of bleeding.

Keywords: Humans; Hemorrhage; Hemodynamics; Tomography; X-ray computed; Angiography

\footnotetext{
* Correspondence: cpmcantwell@gmail.com

'Department of Radiology, St Vincent's University Hospital, Dublin, Ireland

${ }^{4}$ UCD School of Medicine \& Medical Science, Radiology Department and

University College Dublin, St. Vincent's University Hospital, Elm Park, Dublin 4

D04 T6F4, Ireland

Full list of author information is available at the end of the article
}

\section{Springer Open}

( ) The Author(s). 2020 Open Access This article is licensed under a Creative Commons Attribution 4.0 International License, which permits use, sharing, adaptation, distribution and reproduction in any medium or format, as long as you give appropriate credit to the original author(s) and the source, provide a link to the Creative Commons licence, and indicate if changes were made. The images or other third party material in this article are included in the article's Creative Commons licence, unless indicated otherwise in a credit line to the material. If material is not included in the article's Creative Commons licence and your intended use is not permitted by statutory regulation or exceeds the permitted use, you will need to obtain permission directly from the copyright holder. To view a copy of this licence, visit http://creativecommons.org/licenses/by/4.0/. 


\section{Background}

Acute abdominal hemorrhage (AAH) can be intraluminal (upper or lower gastrointestinal bleeding) or extra luminal (bleeding into the parenchyma of an organ, peritoneal cavity or abdominal wall). Acute upper and lower gastrointestinal hemorrhage (GI) treatment guidelines typically suggest endoscopy is the first line investigation (Strate and Gralnek 2016), with CT angiography (CTA), nuclear medicine red cell labelled imaging and conventional angiography (CA) appropriate as second line investigations (ACR appropriateness guidelines). The recently published British Society of Gastroenterology guidelines have advised CTA as first line investigation in hemodynamically unstable patients, prior to endoscopy, CA or surgery (Oakland et al. 2019). Prior studies of CTA in acute GI hemorrhage suggest that patients with a negative CTA are likely to stop bleeding without intervention (Chan et al. 2015; Foley et al. 2010).

There are no specific guidelines for investigating extra luminal hemorrhage in the abdomen outside of the setting of blunt and penetrating trauma (the American Trauma Life Support (ATLS) guidelines). CTA is regularly requested in $\mathrm{AAH}$ with haemodynamic instability by clinical teams and interventional radiologists because CTA can; detect arterial bleeding at low rates of hemorrhage, accurately localize the bleeding point, characterize the etiology (E.G. bleeding ulcer), display the vascular anatomy, determine the arterial access site and aid selection of angiographic equipment.

How best to manage an unstable patient who has an $\mathrm{AAH}$ with a haematoma and no acute vascular findings on CTA represents a difficult clinical scenario for treating physicians and Interventional Radiologists.

The purpose of our study is to review the CA findings and clinical outcome of hemodynamically unstable patients with acute abdominal hemorrhage who had a preceding negative CTA.

\section{Materials and methods}

This retrospective study was approved by our institutional research board. The requirement for patient consent was waived. During the treatment period all GI bleeding was investigated primarily by endoscopy. All acute extraluminal hemorrhage was investigated primarily with CTA. Hemodynamically stable patients with imaging features of recent bleeding (hematoma present) but no acute vascular findings on CTA would undergo inpatient clinical surveillance. Patients who remain hemodynamically unstable after negative CTA and resuscitation would undergo CA despite a normal CTA (Fig. 1).

\section{Patients search}

All CA procedures for acute abdominal hemorrhage performed from 01/01/2010 to 31/12/2017 were identified using a search of the Radiology Information System (RIS). A database entry was generated recording; demographics, suspected aetiology, endoscopy performed, if CTA was performed, time of CTA completion, presence of acute vascular findings on CTA, reasons for not performing CTA, hemodynamic stability at the time of CTA (hemodynamic instability was defined as a sustained systolic blood pressure less than $90 \mathrm{mmHg}$ and heart rate greater than 100 beats/min (Loggers et al. 2017)), hematoma location at CTA (upper and lower GI hemorrhage, parenchymal, peritoneal and abdominal wall bleeding), time of commencing $\mathrm{CA}$, findings at $\mathrm{CA}$, embolic material used and clinical success. Obstetric, penetrating trauma, abdominal aortic and venous bleeding cases were excluded. Only hemodynamically
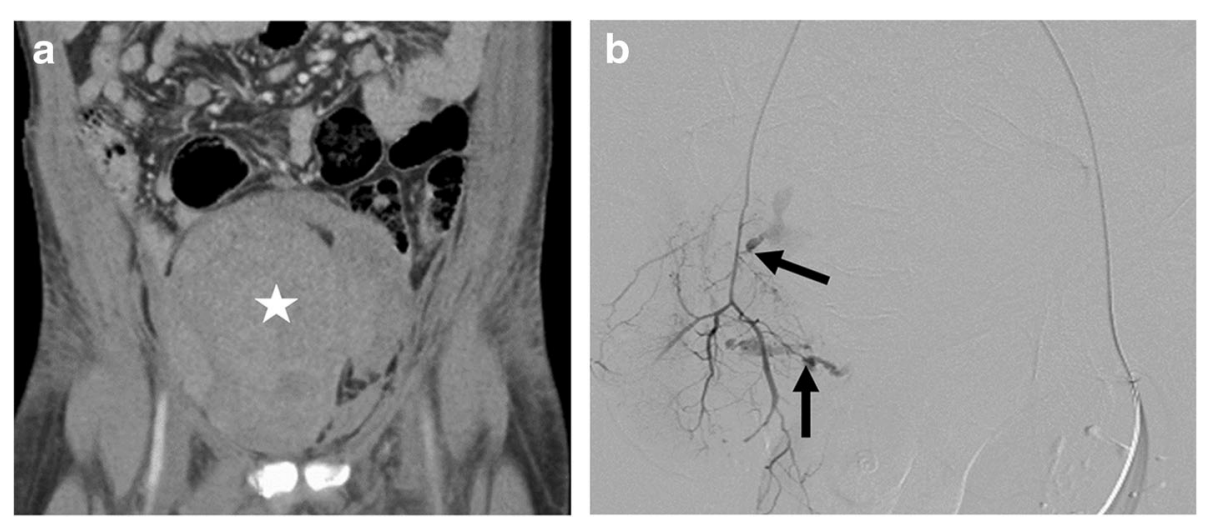

Fig. 1 a. Coronal reconstruction of a negative CTA. A large extraperitoneal hematoma (star) is seen in the pelvis. No active extravasation of contrast or abnormal vessel was seen on CTA. b. Posterior-anterior projection digital subtraction angiogram of the obturator branch of the anterior division of the right internal iliac artery. This was performed using an end-hole catheter inserted from a left common femoral artery access sheath. Active hemorrhage is seen from two branch arteries (black arrows) 
unstable patients who had a negative CTA for acute vascular findings were included in the study.

\section{CT technique}

All CTA studies were performed using a 64-slice CT scanner (Somatom Cardiac CT, Siemens Healthineers, Erlangen, Germany). No oral contrast was administered. Following acquisition of a non-contrast CT abdomen and pelvis range extended from the diaphragm to the symphysis pubis. $150 \mathrm{ml}$ of low-osmolar iodinated contrast $(340 \mathrm{mg} / \mathrm{ml}$ Iodine or higher concentration) was administered by power injector intravenously at $4 \mathrm{ml} /$ sec. Arterial-phase imaging was triggered using bolus tracking in the abdominal aorta at a density threshold of 125 Hounsfield units. The portal-venous-phase was acquired $25 \mathrm{~s}$ later and/or the delayed phase at three minutes after the arterial phase. All CT scans were reconstructed and archived with contiguous thin sections of $1 \mathrm{~mm}$ thickness and routine acquisition and archiving of coronal and sagittal reconstructions. CT scans were primarily interpreted by an abdominal imaging fellowship trained attending.

Active bleeding was defined as the detection of highdensity contrast accumulation in the bowel lumen or an abdominal hematoma between the non-contrast and contrast-enhanced CTA phases. Acute vascular findings included the presence of active bleeding, pseudoaneurysm, truncated/irregular artery or arterio-venous fistula. A hematoma alone on CTA was defined as a negative CTA study.

\section{Angiographic technique}

Angiography was performed using one of two single panel c-arm interventional angiography systems (Artis Q or Axiom DTA angiography suite, Siemens Healthineers, Erlangen, Germany). All procedures were performed via 5-Fr introducer sheath inserted using ultrasound and fluoroscopic guidance into the right common femoral artery. Selective and non-selective digital subtraction angiography was performed with hand or power injection via the suspected bleeding artery (e.g. renal artery) or celiac, superior mesenteric and inferior mesenteric arteries in GI bleeding using 5- $\mathrm{Fr}$ selective angiographic catheters. In some cases, coaxial 1.7-2.3-Fr microcatheters were used for sub-selective angiography. If a hematoma was present on CTA in a vascular territory then non-selective and selective angiography of the vascular territory was performed. If a patient had a percutaneous drain in position and this was the suspected site of bleeding then the drain would be removed over a guidewire and angiography repeated.

Embolization was performed using metal coils or gelatin sponge as a slurry or torpedo selected at the discretion of the operator depending on the vascular anatomy and the lesion site. If the CA was negative, empirical embolization of an arterial territory could be performed at the discretion of the operator.

\section{Imaging review}

All negative CTA studies and subsequent CA procedures were reviewed retrospectively by a fellowship-trained abdominal imaging, vascular IR attending and IR fellow in consensus.

A positive CA was defined as demonstration of active arterial bleeding, presence of a pseudoaneurysm, arteriovenous fistulas or irregular/truncated arteries.

\section{Clinical follow-up}

Patient clinical notes were reviewed for clinical outcome, transfusion need, hemodynamic stability and complications after the CA. Clinical success was defined as absence of symptoms or signs of ongoing bleeding and no further transfusion need.

\section{Patients identified}

160 patients with hemodynamic instability underwent 178 CA procedures for acute abdominal arterial hemorrhage during the study (Fig. 2). 23 patients were referred directly to the angiography suite for CA without a CTA, since there was a known source of arterial bleeding, recurrent bleeding from a known artery or significant hemodynamic instability that in the view of the operator would not allow a delay for CTA. 155 CAs were preceded by CTA. All CTAs were reviewed and confirmed that 140 CTAs demonstrated an acute vascular finding. One CTA was categorized as a positive study as a pseudoaneurysm was identified on retrospective imaging review. 14 CTAs in 13 patients were confirmed on review as negative for acute vascular findings. CA was performed within $2.5 \mathrm{~h}$ of CTA in all cases. The demographics and site of bleeding for these 14 cases are listed in Table 1.

All eight of the acute GI hemorrhage cases underwent endoscopy prior to CTA and CA. For the six upper GI bleeding cases; clips were applied to a bleeding point in one case, a bleeding points was identified but could not be adequately controlled in two cases and no bleeding point was found in three patients (but clot was visualised within the upper GI lumen). Three patients with upper GI bleeding were found to have treatable acute vascular findings at CA. For the two lower GI bleeding cases, one demonstrated hematoma within the colon but no bleeding point. In the other case, a bleeding point was identified at the hepatic flexure and metallic clips were applied. 


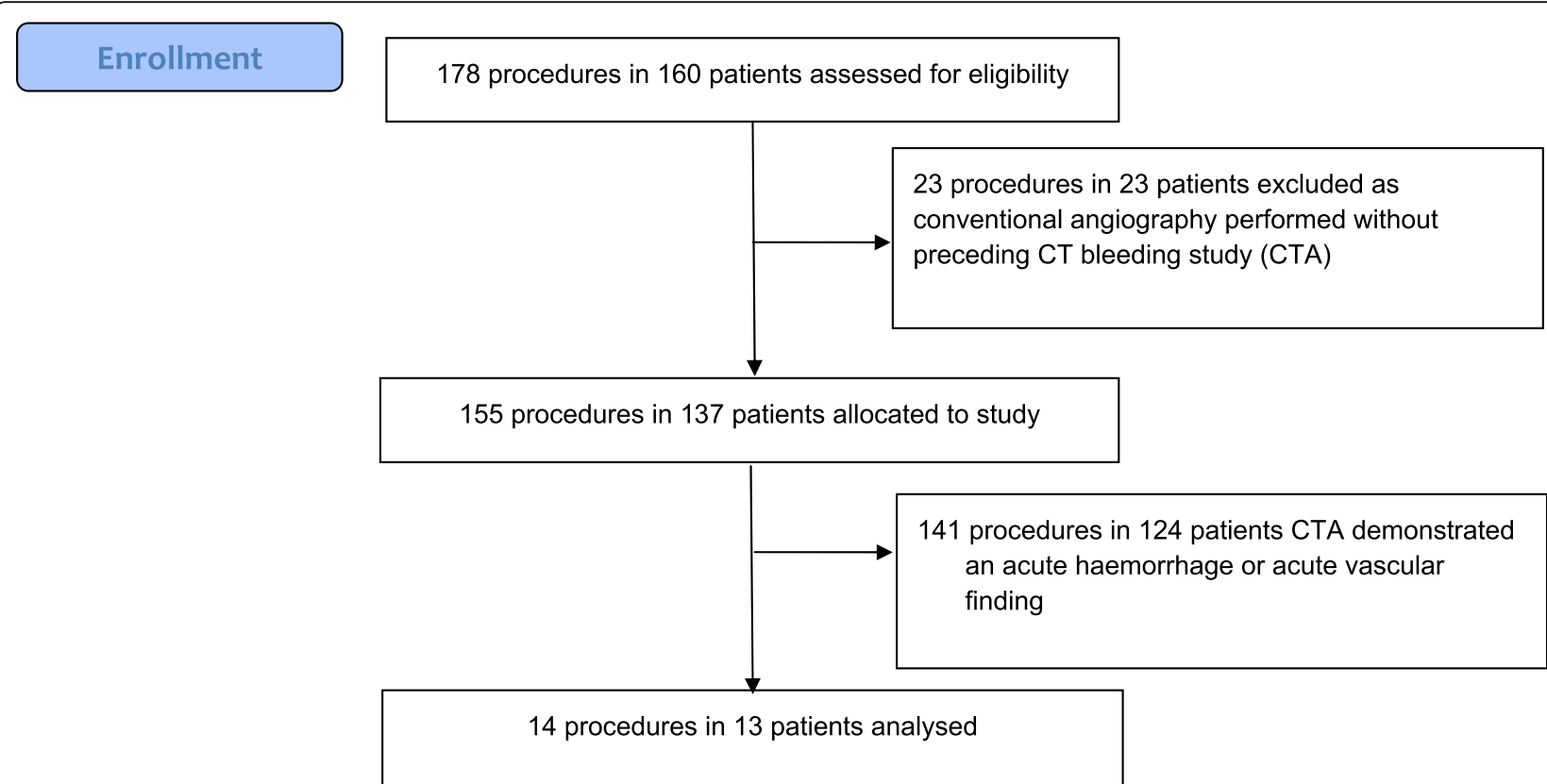

Fig. 2 Flow diagram of patients with hemodynamic instability who underwent conventional angiography (CA) procedures for acute abdominal arterial hemorrhage during the study

\section{Data analysis}

Data was analysed using SPSS version 23. (IBM, New York, USA). Using CA as the gold standard to define a case a positive or negative for an acute vascular finding, contingency tables were created comparing the CTA and CA results for the six anatomical categories of: upper GI, lower GI, renal, liver, abdominal wall and 'other extra-luminal site' bleeding (Table 2). Then $2 \times 6$ categorical tables were created for each of the following categories: false negative, true negative, false positive and

Table 1 Review of the 14 negative CTA studies

\begin{tabular}{|c|c|c|c|c|c|}
\hline $\begin{array}{l}\text { Patient } \\
\text { Number }\end{array}$ & $\begin{array}{l}\text { Age } \\
\text { (years) }\end{array}$ & Sex & Clinical presentation & $\begin{array}{l}\text { Conventional Angiogram } \\
\text { finding }\end{array}$ & $\begin{array}{l}\text { Embolization treatment } \\
\text { delivered }\end{array}$ \\
\hline 1 & 51 & Male & Upper gastrointestinal bleed & Normal & $\begin{array}{l}\text { Empiric treatment with } \\
\text { Gelfoam }\end{array}$ \\
\hline 2 & 29 & Male & Upper gastrointestinal bleed & Active bleeding & Gelfoam and metal coils \\
\hline 3 & 68 & Male & Upper gastrointestinal bleed & Normal & $\begin{array}{l}\text { Empiric treatment with } \\
\text { Gelfoam }\end{array}$ \\
\hline 4 & 71 & Male & Upper gastrointestinal bleed & Normal & $\begin{array}{l}\text { Empiric treatment with metal } \\
\text { coils }\end{array}$ \\
\hline 5 & 56 & Male & Upper gastrointestinal bleed & Abnormal arteries & Gelfoam and metal coils \\
\hline 6 & 43 & Male & Upper gastrointestinal bleed & Active bleeding & Metal coils \\
\hline 7 & 75 & Male & Lower gastrointestinal bleed & Normal & $\mathrm{Nil}$ \\
\hline 8 & 83 & Male & Lower gastrointestinal bleed & Normal & $\mathrm{Nil}$ \\
\hline 9 & 34 & Male & $\begin{array}{l}\text { Extraperitoneal pelvic haematoma post blunt } \\
\text { trauma }\end{array}$ & Active bleeding & Metal coils \\
\hline 10 & 37 & Male & Haematuria post renal biopsy & Pseudoaneurysm & Metal Coils \\
\hline 11 & 72 & Male & Renal cell carcinoma and haematuria & Active bleeding & Metal Coils \\
\hline 12 & 48 & Female & Haematuria post nephrostomy insertion & Active bleeding & Metal Coils \\
\hline 13 -Episode 1 & 39 & Male & $\begin{array}{l}\text { Haematuria after percutaneous } \\
\text { nephrolithotomy }\end{array}$ & Normal & $\begin{array}{l}\text { Empiric treatment with metal } \\
\text { coils }\end{array}$ \\
\hline $\begin{array}{l}13-\text { Episode } \\
2\end{array}$ & 39 & Male & $\begin{array}{l}\text { Haematuria after percutaneous } \\
\text { nephrolithotomy }\end{array}$ & Abnormal arteries & Metal coils \\
\hline
\end{tabular}


Table 2 CTA studies categorised by true/false positive/negative and bleeding site

\begin{tabular}{|c|c|c|c|c|c|c|c|}
\hline & $\begin{array}{l}\text { Upper gastro-intestinal } \\
\text { bleeding }(n=34)\end{array}$ & $\begin{array}{l}\text { Lower gastro-intestinal } \\
\text { bleeding }(n=26)\end{array}$ & $\begin{array}{l}\text { Renal } \\
(n=11)\end{array}$ & $\begin{array}{l}\text { Liver } \\
(n=17)\end{array}$ & $\begin{array}{l}\text { Abdominal / pelvic } \\
\text { wall }(n=17)\end{array}$ & $\begin{array}{l}\text { Other extra-luminal } \\
\text { sites }(n=50)\end{array}$ & $p$ \\
\hline False negative & $3(9 \%)$ & 0 & $4(36 \%)$ & 0 & $1(6 \%)$ & 0 & $<0.001$ \\
\hline True negative & $3(9 \%)$ & $2(8 \%)$ & $1(9 \%)$ & 0 & 0 & 0 & 0.09 \\
\hline False positive & $4(12 \%)$ & $6(23 \%)$ & 0 & $2(12 \%)$ & $1(6 \%)$ & $9(18 \%)$ & 0.46 \\
\hline True positive & $24(71 \%)$ & $18(69 \%)$ & $6(54 \%)$ & $\begin{array}{l}15 \\
(88 \%)\end{array}$ & 15 (88\%) & $41(82 \%)$ & 0.18 \\
\hline Sensitivity & $89 \%$ & $100 \%$ & $60 \%$ & $100 \%$ & $94 \%$ & $100 \%$ & \\
\hline Specificity & $43 \%$ & $25 \%$ & $100 \%$ & NA & NA & NA & \\
\hline $\begin{array}{l}\text { Positive } \\
\text { predictive value }\end{array}$ & $85 \%$ & $75 \%$ & $100 \%$ & $88 \%$ & $94 \%$ & $82 \%$ & \\
\hline $\begin{array}{l}\text { Negative } \\
\text { predictive value }\end{array}$ & $51 \%$ & $100 \%$ & $20 \%$ & NA & NA & NA & \\
\hline
\end{tabular}

NA Not assessed

true positive. Fishers exact test was then applied to these categorical tables, to compare the proportion of false negative etc. cases between the six anatomical categories. The Fisher's exact test was chosen because of the expected high proportion of values $<5$ within the Tables. A $P$ value of $<0.05$ was considered significant.

\section{Results}

\section{Imaging review}

The CA was positive for an acute vascular finding in eight of the 14 negative CTA cases. In those eight cases the following findings were demonstrated: active bleeding (5 patients), pseudoaneurysm (1) and abnormal artery (2).

\section{Clinical follow-up}

Arterial embolization was performed in twelve of the fourteen CA procedures. In all eight cases with a target acute vascular lesion on CA, this was treated with embolization. Six cases had no acute vascular lesion on CA. In four of these negative CA cases empiric embolization was performed. Two remaining negative CA resulted in no embolization (Table 1).

One patient underwent two procedures. This patient had renal tract hemorrhage post nephrolithotomy. $\mathrm{He}$ had a negative CTA, but remained hemodynamically unstable and therefore underwent initial negative $\mathrm{CA}$ and empiric embolization using two $6 \mathrm{~mm}$ Nester coils deployed in the accessory left renal artery. He represented with frank haematuria on day 12 post embolization. A CTA showed a small hematoma in the left renal pelvis and bladder but no active bleeding. He then had a second CA which demonstrated irregularity of a lower pole renal artery branch vessel, which was treated with embolization using $3 \mathrm{~mm}$ vortex micro coils.

None of the patients required further blood transfusion in the follow up period. All patients clinically improved and demonstrated no signs of further haemodynamic instability or bleeding. Therefore, the clinical success rate of positive CA with embolization was $100 \%(8 / 8)$. The clinical success rate of negative CA with empiric embolization was $75 \%$ (3/4). No complications or deaths occurred within 30 days of CA.

\section{Data analysis}

The proportion of true/false negative and positive cases is detailed in Table 2. Regarding the false negative cases, there was a significant difference between the groups $(p<0.001)$, with $4 / 11(36 \%)$ of CTA studies false negative for renal heamorrhage, compared to $3 / 34$ (9\%) for upper GI bleeding and 1/17 (6\%) for abdominal / pelvic wall bleeding cases. There were no false negative CTA studies in patient with liver hemorrhage $(n=17)$ or for the other sites of extra-luminal hemorrhage (peripancreatic, splenic, mesenteric). There was no significant difference between groups when comparing the proportions of true negative, false positive or true positive cases (Table 2).

\section{Discussion}

In this cohort of hemodynamically unstable patients with acute arterial abdominal hemorrhage, 57\% (8/14 patients) of those with no acute vascular findings on CTA demonstrated a treatable target lesion on CA. Therefore, absence of acute vascular findings on CTA should not exclude consideration for CA and embolization if the patient is unstable.

In cases of luminal GI hemorrhage, our results demonstrate a higher number of false negative CTAs for upper GI hemorrhage compared to lower GI hemorrhage. This is in line with previously published literature, which has shown that upper GI hemorrhage has a significantly 
higher false negative CTA rate and that in patients with a lower GI bleed (Chan et al. 2015).

Regarding extraluminal hemorrhage, cases of renal hemorrhage demonstrated the highest proportion of false negative CTA studies (36\%) in our cohort. Three out of four of these patients were iatrogenic injuries due to a renal biopsy or nephrolithotomy. An article comparing CTA and CA for renal hemorrhage found that of fourteen patients who had negative results on CTA, nine (64\%) were found to have treatable acute vascular lesions on CA, which were successfully treated with coil embolization (Mao et al. 2015). In the single case where we performed $\mathrm{AE}$ on two occasions, the injured artery in the renal parenchyma may have been in spasm and intermittently bleeding, hence not visualized on the initial CTA or CA. An empiric lower pole embolization was performed at the first $\mathrm{AE}$ procedure on an accessory renal artery.

There are limitations in our study; our small study population comprised a unique cohort of patients with $\mathrm{AAH}$ in a single centre, all of whom underwent CA and CTA. However, we did not capture all presentations to our centre with a clinical diagnosis of $\mathrm{AAH}$, since some patients with GI hemorrhage will go straight to endoscopy for management at our centre, without a CTA. Therefore, it was not possible to calculate sensitivity of CTA for source of GI hemorrhage with our collected data. AAH is intermittent due to the body's response to bleeding (including vessel spasm and vessel thrombosis). Therefore, comparison of two diagnostic tests is difficult when they are performed at two different time points.

\section{Conclusion}

In a cohort of hemodynamically unstable patients, $57 \%$ (8/14) of cases with no acute vascular findings on CTA demonstrated a source of hemorrhage on CA. The false negative rate of CTA was significantly higher for renal tract hemorrhage compared to other sites of bleeding.

\section{Acknowledgements}

Not applicable.

\begin{abstract}
Authors' contributions
ACOB, GMH, NR, AP, JWJMC, CPC made substantial contributions to the conception, design of the work; the acquisition, analysis, interpretation of data; the creation of new software used in the work; have drafted the work or substantively revised it AND have approved the submitted version; AND have agreed both to be personally accountable for the author's own contributions and to ensure that questions related to the accuracy or integrity of any part of the work, even ones in which the author was not personally involved, are appropriately investigated, resolved, and the resolution documented in the literature. The authors read and approved the final manuscript.
\end{abstract}

Availability of data and materials

All data generated or analyzed during this study are included in this published article.

Ethics approval and consent to participate

Ethics approval was received for this retrospective study.

\section{Consent for publication}

The authors and patients have consented for publication, availability of data and materials.

\section{Competing interests}

The authors declare that they have no competing interests.

\section{Author details}

${ }^{1}$ Department of Radiology, St Vincent's University Hospital, Dublin, Ireland. ${ }^{2}$ Department of Medicine, St Vincent's University Hospital, Dublin, Ireland. ${ }^{3}$ University of Glasgow Medical School, Glasgow, UK. ${ }^{4}$ UCD School of Medicine \& Medical Science, Radiology Department and University College Dublin, St. Vincent's University Hospital, Elm Park, Dublin 4 D04 T6F4, Ireland.

Received: 4 January 2020 Accepted: 21 February 2020

Published online: 20 April 2020

\section{References}

Chan V, Tse D, Dixon S et al (2015) Outcome following a negative CT angiogram for gastrointestinal hemorrhage. Cardiovasc Intervent Radiol 38:329-335

Foley PT, Ganeshan A, Anthony S, Uberoi R (2010) Multi-detector CT angiography for lower gastrointestinal bleeding: can it select patients for endovascular intervention? J Med Imaging Radiat Oncol 54:9-16

Loggers SAI, Koedam TWA, Giannakopoulos GF, Vandewalle E, Erwteman M, Zuidema WP (2017) Definition of hemodynamic stability in blunt trauma patients: a systematic review and assessment amongst Dutch trauma team members. Eur J Trauma Emerg Surg 43:823-833

Mao Q, Zhong B, Lin Y et al (2015) Clinical application of computed tomographic angiography in patients with renal arterial hemorrhage: diagnostic accuracy and subsequent therapeutic outcome. Exp Ther Med 10:508-512

Oakland KG, Chadwick JE et al (2019) Diagnosis and management of acute lower gastrointestinal bleeding: guidelines from the British Society of Gastroenterology. Gut 68:776-789

Strate LL, Gralnek IM (2016) ACG clinical guideline: Management of Patients with Acute Lower Gastrointestinal Bleeding. Am J Gastroenterol 111:459-474

\section{Publisher's Note}

Springer Nature remains neutral with regard to jurisdictional claims in published maps and institutional affiliations.

\section{Submit your manuscript to a SpringerOpen ${ }^{\bullet}$ journal and benefit from:}

- Convenient online submission

- Rigorous peer review

- Open access: articles freely available online

High visibility within the field

- Retaining the copyright to your article

Submit your next manuscript at $>$ springeropen.com 